\title{
O QUE DIZEM OS PROFESSORES DA UNIVERSIDADE DE AVEIRO - PT SOBRE A MOBILIDADE DOS ESTUDANTES DA UNEMAT E A APRENDIZAGEM DA MATEMÁTICA
}

\section{THE TEACHERS OF THE UNIVERSITY OF AVEIRO-PT, ON THE MOBILITY OF THE STUDENTS UNEMAT AND LEARNING MATH UNEMAT}

\section{Maria Elizabete Rambo Kochhann}

Universidade de Estado de Mato Grosso (Unemat) - câmpus Barra do Bugres

E-mail: beterambo@gmail.com

\section{Dayse Cristine Dantas Brito Neri de Souza}

universidade de Aveiro

E-mail: dayneri@ua.pt

\section{Resumo}

O Programa de Licenciatura Internacional - PLI, um programa de mobilidade acadêmica financiado pela Capes, teve a Unemat participando pela primeira vez na edição 2013-2015, com estudantes da Licenciatura em Matemática na Universidade de Aveiro - UA, Portugal. A temática da mobilidade está apoiada pelos teóricos Siegler (2009), Reyes (2012), Veiga (2011) e De Witt (1998), entre outros. Apresentamos um breve histórico da mobilidade na Unemat para se perceber a importância dessa experiência para as Licenciaturas e a Matemática. A natureza do estudo foi qualitativa, e as entrevistas foram realizadas com professores da UA. Por fim, observamos que os referidos estudantes conquistam os resultados almejados, mas as IES brasileiras poderiam contribuir mais ofertando uma melhor base em Matemática aos estudantes.

Palavras-chave: mobilidade. PLI. aprendizagem de matemática.

\section{Abstract}

The Abroad Licenciate Program - PLI is an academic mobility program for graduate degree courses focused on teaching in primary and secondary schools. It was funded by Capes and Unemat first participated in the 2013-2015 edition with students of the degree in Mathematics at the University of Aveiro - UA, Portugal. The mobility theme is supported by the theories of Siegler (2009), Reyes (2012), Veiga (2011) and De Witt (1998), among others. It presents a brief history of mobility in Unemat to show the importance of this experience for Undergraduate courses and mathematics. The nature of the study was qualitative, and interviews were held with the UA teachers. Finally, we observed that these students achieved the objectives, but the Brazilian graduate institutions could contribute more offering a better mathematical foundation to students.

Palavras-chave: mobility. PLI. mathematics learning. 


\section{INTRODUÇÃO}

Os professores da Licenciatura em Matemática da Unemat/câmpus Barra do Bugres - MT, desde o ano de 2010, têm conseguido apoio da Coordenação de Aperfeiçoamento do Pessoal do Ensino Superior - Capes por meio da aprovação de projetos que visam a uma integração e crescimento na relação Universidade-escola. Foi no princípio desse processo que, com um contato maior com as unidades escolares, foi iniciado um trabalho pela valorização das licenciaturas. Um dos aspectos desse trabalho se refere à forma permanente de manter os estudantes da Licenciatura em Matemática nas escolas de Educação Básica promovendo atividades com os alunos para as quais foram antes capacitados. Do estreitamento dessas relações houve demandas as mais variadas, dentre que podemos destacar a necessidade de oferta de trabalhos mais qualificados na formação inicial de professores e de atividades que atendessem aos alunos de hoje, ligadas à valorização das interações professor $x$ aluno, aluno x conhecimento e conhecimento x uso das Tecnologias de Informação e Comunicação - TICs.

Diante das demandas, iniciamos a busca de oportunidades para estudantes das licenciaturas, uma vez que muitos deles revelavam grande poder de superação e vontade de estudar mais e melhor. Um dos obstáculos era o trabalho remunerado que exerciam. No entanto, a remuneração era necessária para ajudar na manutenção dos gastos pessoais e universitários.

No sentido de responder a essa vontade de estudar mais e melhor, implantamos um projeto com seis bolsistas pagos pela Capes, que atuavam nas escolas de Barra do Bugres e região, com a coordenação do programa OBEDUC ${ }^{1}$. O projeto inicial teve o incremento de outros, também aprovados, e mais bolsas foram oportunizadas. O processo foi se tornando um diferencial nas salas de aula, tendo em conta que os bolsistas que atuavam nos projetos, além de desenvolverem atividades nas escolas, tinham tempo para se dedicar aos estudos e

1 O Programa Observatório da Educação, resultado da parceria entre a Capes e o INEP, foi instituído pelo Decreto Presidencial no 5.803, de 08 de junho de 2006, com o objetivo de fomentar estudos e pesquisas em educação que utilizem a infraestrutura, disponível das Instituições de Educação Superior - IES e as bases de dados existentes no INEP. O programa visa, principalmente, proporcionar a articulação entre pósgraduação, licenciaturas e escolas de educação básica e estimular a produção acadêmica e a formação de recursos pós-graduados, em nível de mestrado e doutorado. Disponível em: <http://www.capes.gov.br/educacao-basica/observatorio-da-educacao>. Acesso em: 7 out. 2014. 
oportunidades de participar em diferentes eventos e formações.

Com o objetivo de oferecer uma formação mais qualificada aos estudantes, a CAPES abriu o edital do Programa de Licenciatura Internacional em março de 2013. Surgiu a possibilidade de conciliar as duas propostas. Oportunizar participação a estudantes da Unemat, no Brasil, com envolvimento em programas e projetos e, a outros, apresentar a viabilidade de estudar em uma universidade estrangeira com uma proposta bem mais ousada de formação inicial.

Diante da oferta apresentada pela CAPES, optou-se pelo Programa de Licenciatura Internacional - PLI Portugal de no 017/2013. Após uma leitura bem atenta e feita uma análise dos possíveis parceiros que satisfizessem as exigências do edital, encontramos três professores. Foi elaborada a proposta e contatada a Diretoria de Gestão de Mobilidade Acadêmica - DMA para os acertos institucionais necessários, visto que sem estes os estudantes seriam penalizados com a quantidade de requisitos exigidos na Licenciatura em Matemática da Unemat. Um dos requisitos que se revelaram de grande preocupação diz respeito aos Estágios Curriculares Supervisionados I, II, III e IV, que não podiam ser concomitantes. Deste modo, seriam necessários mais quatro semestres aos estudantes no regresso dos estudos da Universidade de Aveiro (UA), o que exigiria dos mesmos um tempo de integralização mínimo de 5 anos e meio para os que ingressaram no primeiro semestre de 2012. Resolvidos todos os procedimentos, o projeto foi submetido. O PLI na Unemat foi aprovado com uma proposta para a Licenciatura em Matemática do câmpus Barra do Bugres.

Posteriormente à aprovação, vieram as etapas para a escolha dos discentes com critérios bem definidos no projeto submetido e os passos a serem seguidos para cumprimento das exigências do edital. Por fim, o que seria essa experiência em mobilidade internacional para os estudantes? O que pensam os docentes da Universidade de Aveiro acerca dos estudantes da UNEMAT? Quais os contributos que o PLI trará aos alunos da UNEMAT, na perspectiva dos professores? O presente estudo tem como objetivo responder a estas questões. 


\section{CONTEXTUALIZAÇÃO TEÓRICA: MOBILIDADE}

Internacionalização, no projeto PLI, tem como finalidade, segundo os editais lançados desde o ano de 2010, ajustar as matrizes curriculares das licenciaturas, acompanhar os projetos propostos e avaliar os impactos deles decorrentes, propiciar comunicação permanente entre as instituições envolvidas, sistematizar informações sobre o programa e, ainda, de acordo com o edital de 2014, a tarefa por parte da equipe proponente é efetuar as missões de trabalho e realizar pesquisa na instituição de ensino estrangeira.

Sem dúvida que esse acréscimo, quanto à pesquisa conjunta reforça um dos objetivos maiores que está subjacente ao conceito de internacionalização presente nos escritos de autores tais como De Witt (1998), Knight (1999), Siegler (2009), Siegler et al. (2009) Veiga (2011) e Reyes (2012), que apontam a internacionalização como um conjunto de ações que visam a apoiar reformas curriculares, pesquisa em conjunto, celebração de acordos internacionais e intercâmbio de estudantes e professores enquanto ações mais frequentes que tenham em vista o processo de sustentabilidade da internacionalização das instituições.

Siegler (2009) e Reyes (2012) afirmam que o processo de internacionalização das universidades é decorrência da globalização, conceito que anteriormente fora estudado por Yang, (2002) citado por Jofin (2009), Knight (1994) e De Witt (apud VEIGA, 2011). Veiga (2011, p.3) faz referência à internacionalização como "[...] um conjunto de atividades destinadas a fornecer uma experiência educacional num ambiente que integra uma perspectiva global".

Em Veiga (2011) podemos observar que a Capes não teve, ao formular os editais do PLI, a intenção de construir uma história sem precedentes: apenas viabilizou aos docentes que atuam nas licenciaturas a formulação de projetos que possibilitam a composição de grupos de estudantes para participarem do programa, acrescentando também a exigência um pouco menor que os 600 pontos requeridos para a mobilidade no Programa Ciência sem Fronteira, nas primeiras edições de editais. 
Dentre as mudanças verificadas, vê-se que no edital no 74/2014, que consta em Brasil (2014), foi incluída a exigência de uma pontuação mínima, mesmo sabendo-se que os que procuram as licenciaturas são estudantes com desempenho não tão elevados pela desvalorização da profissão docente no Brasil. Além desse requisito há outros critérios a serem seguidos, tais como: a duração da permanência ser de um ano (antes, a obtenção da dupla diplomação era apresentada como possibilidade a todos, e a permanência era de dois anos para os que atingiam os 48 ECTS no primeiro ano); o aluno ter cursado o Ensino Médio em escolas públicas ou na condição de bolsista; ter uma integralização com no mínimo $20 \%$ do curso e no máximo $80 \%$, feitos na instituição de origem.

Temos consciência de que as estratégias e políticas de internacionalização das universidades estão em um processo bastante inicial, mas que para se obter êxito são necessárias ações conjuntas entre os pesquisadores, decorrentes ou não da celebração de acordos. Cabe salientar que, sempre que os acordos se realizam, ampliam-se as possibilidades de êxito desde que haja cobranças institucionais, pois isto requer dos participantes registros e divulgações sobre as realizações que ocorreram, os avanços, dificuldades e resultados. Para Reyes,

\begin{abstract}
“[...] ações como a investigação conjunta, os acordos institucionais, o intercâmbio de estudantes, professores e funcionários são pontos fundamentais que definirão um processo de internacionalização bem sucedido nas Instituições de Ensino Superior." (2012, p. iii)
\end{abstract}

Na avaliação de Reyes (2012) e Siegler (2009), as cooperações internacionais são entendidas como meios de desenvolvimento institucional e complementar das próprias capacidades das instituições que oportunizam realizar atividades conjuntas objetivando uma integração com finalidades acordadas e mútuas. Segundo Knight (apud SIEGLER, 2009) e Reyes (2012) percebe-se existirem "[...] pontos fortes (consciência e abertura por parte dos atores envolvidos no processo de internacionalização); pontos em fase de desenvolvimento 
(planejamento) e pontos frágeis (operacionalização, implementação e efeito de integração)", nas palavras de Reys (2012). Com algumas alterações, as convergências dos autores supracitados são: em pontos fortes, a "consciência", em pontos em fase de desenvolvimento, o "planejamento" e, nos pontos frágeis a "implementação e efeito de integração". E nesta perspectiva que analisamos nas falas dos entrevistados como eles olham e avaliam essa vivência de mobilidade proposta por um grupo de professores sem experiência neste contexto, mas que com muito empenho tem se debruçado na busca de melhor compreender o processo para que os estudantes que dela participam alcancem o sucesso esperado.

É possível também perceber que não é tão simples a internacionalização. São muitos os mitos construídos ao longo das últimas décadas do século XX e no início do século XXI. Entre eles, as teorias de De Witt (1998), Siegler (2009), Reyes (2012) e Veiga (2011). Estudo de Veiga (2011) expressa que "O grau de internacionalização é estabelecido a partir de três áreas previamente selecionadas da revisão de literatura: ensino/aprendizagem, cooperação e investigação" (p. v). Para a mesma autora, o termo "internacionalização", com apoio em Yang (2002 citado por Jofin, 2009), inclui diferentes dimensões e depende do nível da educação superior em questão. Veiga $(2011$, p.3) afirma ainda, que essas dimensões compreendem um conjunto de atividades que oferecem "[...] uma experiência educacional num ambiente que integra uma perspectiva global". Um dos mitos da internacionalização institucional refere-se por vezes à quantidade de protocolos internacionais assinados pelas instituições, dos quais muitas não conseguem tirar benefícios. Por outro lado, segundo Veiga (2011, p.84), as IES que têm um maior número de protocolos em vigor são as que têm também maior quantidade de estudantes em mobilidade.

Derin et al. (2009, p. 1615), pesquisadores que estudaram a mobilidade enquanto dimensão cultural em professores turcos no ensino da língua inglesa, encontrou enquanto eleição pelos participantes as seguintes prioridades: "construir bons relacionamentos com os alunos', 'ajudar os alunos a adquirir conhecimento e habilidades que precisam para a vida' e 'ajudar os alunos a adquirir conhecimento e habilidades que eles precisam para aprendizagem de 
línguas estrangeiras". Avaliamos que essas habilidades são importantes para qualquer atividade de mobilidade para todas as áreas do conhecimento, pois em uma primeira indicação aos estudantes que participam da experiência PLI, ora apresentada, essas prioridades também foram sugeridas.

Nos estudos realizados por Veiga (2011) sobre a internacionalização das universidades portuguesas, a pesquisadora buscou estabelecer um ranking das abordagens possíveis de serem internacionalizadas, a saber: atividade, resultados, motivação, processo, carácter, estrangeira/além fronteira. A modalidade de mobilidade nesta internacionalização do programa PLI é muito mais considerada como processo e caráter, definições assumidas por Veiga (2011), já que no processo há a integração

\footnotetext{
“[...] de uma maneira sustentável nas três funções primárias de uma instituição: ensino/aprendizagem, investigação e serviço à sociedade", e o caráter se apoia no "[...] entendimento internacional/intercultural e foca-se nas atividades domésticas ou baseadas no câmpus".
}

Também segundo Veiga (2011), tais ações centram-se em aspectos curriculares, extracurriculares e organizacionais de uma instituição e são consideradas funções primárias. Para estarem no nível secundário, a autora aponta aspectos como a dimensão internacional no currículo, desenvolvimento internacional de projetos e programas acadêmicos conjuntos. Um destes itens já aparece no edital PLI 2014: o desenvolvimento internacional de projetos. A preocupação dos editais da Capes na implantação do programa PLI foi que este viesse de alguma forma impactar no sentido de "[...] diversificar o currículo dos cursos de licenciatura brasileiros, tendo como prioridade o aperfeiçoamento e a valorização da formação de professores para a educação básica, além de ampliar as oportunidades de formação de estudantes", conforme Brasil (2010). O documento visa, ainda, enquanto objetivos, a

\footnotetext{
“Ampliar a formação de docentes para o ensino básico no contexto nacional; Ampliar e dinamizar as ações voltadas à formação de professores,
} 
priorizando a formação inicial desenvolvida nos cursos de licenciatura; Apoiar a formulação e implementação de novas diretrizes curriculares para a formação de professores, com ênfase no Ensino Fundamental e no Ensino Médio; entre outros". (2010, p. 1)

Podemos ver claramente que a ênfase as abordagens de processo e caráter citadas por Veiga (2011), o ensino/aprendizagem, a investigação e um serviço mais qualificado a ser posteriormente oferecido à sociedade brasileira, é o que se requer dos acadêmicos da Unemat e se encontra na proposta do projeto. A Capes é que tarda em fazer uma cobrança mais formal em termos de documentação, tendo em vista o financiamento alto dessa proposta. A experiência de dois anos em uma Universidade portuguesa, possivelmente, apresentará importantes contribuições aos currículos dos estudantes. Acerca dos contributos, Rudzki (1995) aponta quatro dimensões: mudança organizacional, inovação do currículo, desenvolvimento do staff e mobilidade de estudantes. Dimensões essas que devem estar claras nas adesões aos programas de internacionalização por parte das instituições.

Siegler e Miura (2012) alertam para a necessária separação entre globalização e internacionalização. Esta última compreende aspectos locais e alguns de abrangência internacional. Na mesma direção, Santos e Cordeiro (2015) entendem que a vertente da internacionalização abre possibilidades para que cada universidade concretize e defina "[...] uma agenda autônoma de diplomacia cultural universitária - que lhe confere um carácter mais inovador e que abre à universidade um vasto campo de desafios e oportunidades". Para Siegler (2009), tanto os aspectos locais como os internacionais são considerados interculturais, o que exige formulação de estratégias e de políticas de internacionalização para nortear o planejamento da estruturação organizacional e de apoio às ações como pesquisas conjuntas, reformas curriculares, celebração de acordos internacionais, intercâmbio de estudantes e professores, sendo estes últimos os pontos fundamentais em um processo sustentável de internacionalização da instituição. 
A importância desse processo de internacionalização é salientada por Santos e Cordeiro (2015, p.133) ao falarem dos projetos em rede, das trocas de experiências e de aferição de boas práticas as quais podem ser reforçadas nos "[...] projetos de investigação individuais ou de equipa", e citarem o "leque de propostas de formação (dupla diplomação, diplomas conjuntos, diplomação plena no estrangeiro), a mobilidade estudantil e de pessoal docente e não docente", entre outros tantos aspectos que poderíamos destacar. Como o foco deste artigo é a percepção dos professores sobre a mobilidade de estudantes que visam à dupla diplomação se obtiverem os 120 ETCs durante o período de dois anos de permanência em uma universidade de Portugal, grande é a relevância que estes pontos têm para o presente trabalho.

\subsection{Processo de Bolonha e mobilidade}

O Processo de Bolonha, um acordo voluntário entre Instituições de Ensino Superior em toda a Europa, também contempla a mobilidade de estudantes, e para utilizar isso cada uma das IES precisou fazer a normatização para tal modalidade. A Universidade de Aveiro (2011, p.2) relata, ao falar da modalidade que adotou, na Alínea "I - "Estudante em mobilidade" - o estudante matriculado e inscrito num dado curso e estabelecimento de ensino superior que realiza parte desse curso noutro estabelecimento de ensino superior, com o qual a UA celebrou um acordo de mobilidade".

A Universidade de Aveiro também estabeleceu critérios para inscrição em unidades curriculares, no seu artigo 9.ํ, estipulando um limite máximo de 76 créditos anuais, dependendo de aprovação em ano anterior por no mínimo 40 créditos. Apresentamos neste ponto apenas um dos inúmeros critérios diferentes encontrados pelos estudantes brasileiros na UA. Diante das alterações nas realidades curriculares e de organização, apontamos algumas dimensões da Universidade de Aveiro. A UA, com um número de estudantes em torno de 15.000, tem a missão de

Criar conhecimento, expandir o acesso ao saber em benefício das pessoas e da sociedade, através da investigação, do ensino e da cooperação; assumir 
um projeto de formação global do indivíduo; ser ator na construção de um espaço europeu de investigação e educação, e de um modelo de desenvolvimento regional assente na inovação e no conhecimento científico e tecnológico. $(2011$, p. 6$)$

Por outro lado, a Unemat possui em seus câmpus alguns cursos, apenas, e seus estudantes, ao se depararem com as dimensões da UA, encontraram barreiras para localizar o Calendário Escolar e os Horários das disciplinas que iriam frequentar na UA, segundo o artigo 37․ De acordo com as exigências da Capes, os alunos devem cursar pelo menos uma disciplina pedagógica por semestre. Essas disciplinas são ministradas nas Licenciaturas na Educação, que possuem duas opções (Educação Básica e Psicologia); nos mestrados acadêmicos (dez opções); e/ou nos mestrados profissionais (sete opções a escolher). As escolhas de disciplinas, feitas conjuntamente pelas equipes do projeto e acordadas entre as coordenações da UA e Unemat, por vezes não conseguiam possibilitar que os estudantes frequentassem as disciplinas necessárias devido aos horários. Foi preciso considerar todo este cenário curricular da UA para se escolherem opções que pudessem cumprir ao mesmo tempo os objetivos dos estudantes, as exigências da Capes e o aproveitamento das mesmas pela Unemat.

\subsection{Unemat e mobilidade}

Em conformidade com a Diretoria de Gestão de Mobilidade Acadêmica - DMA, a denominação mobilidade para a Unemat, refere-se a um

\footnotetext{
“[...] vínculo temporário de acadêmicos com diferentes instituições públicas de ensino superior conveniadas nacionais ou estrangeiras, ou com os diferentes campi da UNEMAT, com o objetivo de proporcionar o enriquecimento da formação acadêmica dos estudantes, por meio da vivência nas diversas culturas do país e do exterior". (2014, p. 1)
}

O mencionado vínculo começou a ser promovido aos estudantes com os primeiros 
deslocamentos feitos no segundo semestre do ano de 2013. Essa possibilidade foi criada a partir do programa Ciências sem Fronteira, do Ministério da Educação, que, segundo Brasil (2011, p.1), “é um programa que busca promover a consolidação, expansão e internacionalização da ciência e tecnologia, da inovação e da competitividade brasileira por meio do intercâmbio e da mobilidade internacional". Tal consolidação se dará se perseguidos os objetivos preconizados no decreto Brasil, quais sejam:

\begin{abstract}
"Investir na formação de pessoal altamente qualificado nas competências e habilidades necessárias para o avanço da sociedade do conhecimento; Aumentar a presença de pesquisadores e estudantes de vários níveis em instituições de excelência no exterior; Promover a inserção internacional das instituições brasileiras pela abertura de oportunidades semelhantes para cientistas e estudantes estrangeiros; Ampliar o conhecimento inovador de pessoal das indústrias tecnológicas; Atrair jovens talentos científicos e investigadores altamente qualificados para trabalhar no Brasil”. (2011, p.1)
\end{abstract}

O programa Ciências sem Fronteira oferece aos selecionados por meio da Capes as garantias financeiras para a permanência no país com a finalidade de que se cumpra o que foi acordado entre ambas as partes (estudantes e IES envolvidas). Neste estudo, apresentamos dados da mobilidade levantados na DMA em 2014 que mostram como os alunos da Unemat estão conseguindo participar dessa oportunidade ofertada a estudantes brasileiros no quesito mobilidade.

Cabe também esclarecer que na Unemat a mobilidade foi definida em três modalidades: Mobilidade Acadêmica Intercampi; Mobilidade Acadêmica Nacional; e Mobilidade Acadêmica Internacional. Temos ainda uma particularidade que é a Mobilidade Nacional dentro do próprio estado, a qual foi aproveitada por sete estudantes, entre 2013 e 2014 que se deslocaram para a capital do estado Cuiabá, estudando na UFMT. A Intercampi beneficiou dois estudantes, e a Nacional, um. Foi 41 o número de alunos que participaram ou participam da Mobilidade Internacional, conforme dados apresentados nos gráficos abaixo. 
No gráfico 1 , os dados se referem ao país ou localidade de destino dos estudantes e candidatos por semestre.

Gráfico 1. País ou localidade de destino dos estudantes da Unemat em mobilidade.

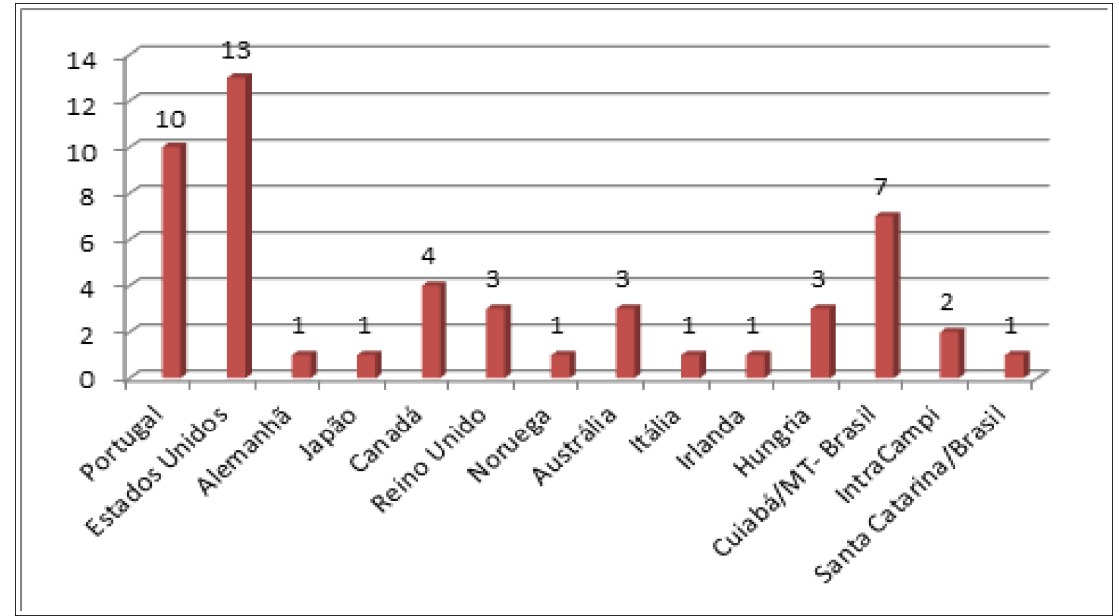

Fonte: dados da pesquisa.

O gráfico 2 traz o semestre e a quantidade de estudantes que participaram do Programa Ciências sem Fronteira. Outros alunos agraciados pela oportunidade desistiram, possivelmente pelo desafio que representa a proposta de mobilidade.

Gráfico 2. Número de estudantes da Unemat em mobilidade por semestre.

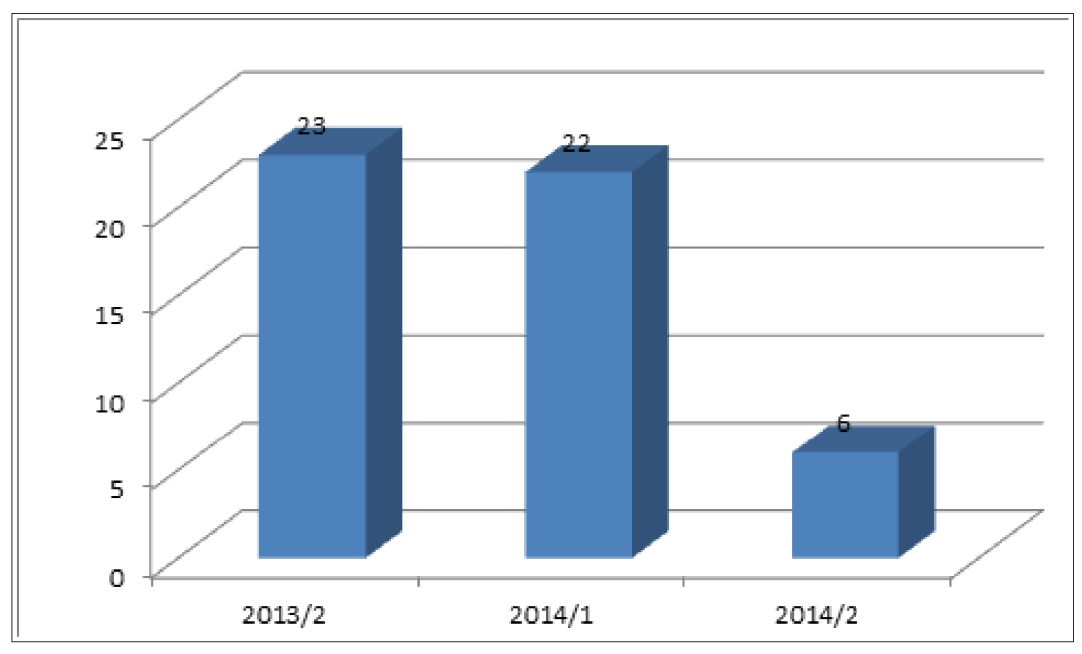

Fonte: dados da pesquisa.

Relativamente à realidade por período, no ano de 2014 houve mais estudantes em 
mobilidade. No entanto, por semestre, ainda foi no segundo semestre de 2013 que se alcançou uma maior participação de estudantes em mobilidade na Unemat, conforme pode ser visto no gráfico 2 acima. É exatamente nesse semestre que se computam os sete alunos do projeto PLI foco desta investigação.

Gráfico 3. Estudantes da Unemat em mobilidade por câmpus.

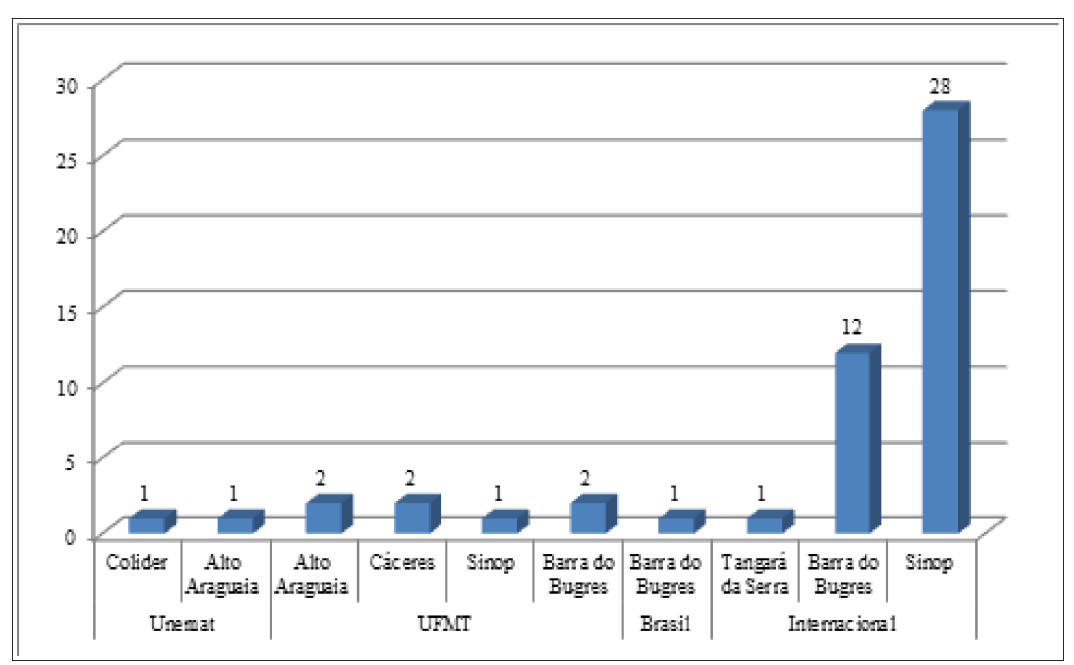

Fonte: dados da pesquisa.

Temos ainda o número de estudantes por curso e por destino, que se vê abaixo no Gráfico 4. Entendemos que os dados ora apresentados revelam informações que consideramos pertinentes para se compreender o que levou a equipe a submeter uma proposta ao PLI.

Gráfico 4. Estudantes da Unemat em mobilidade por curso e por destino.

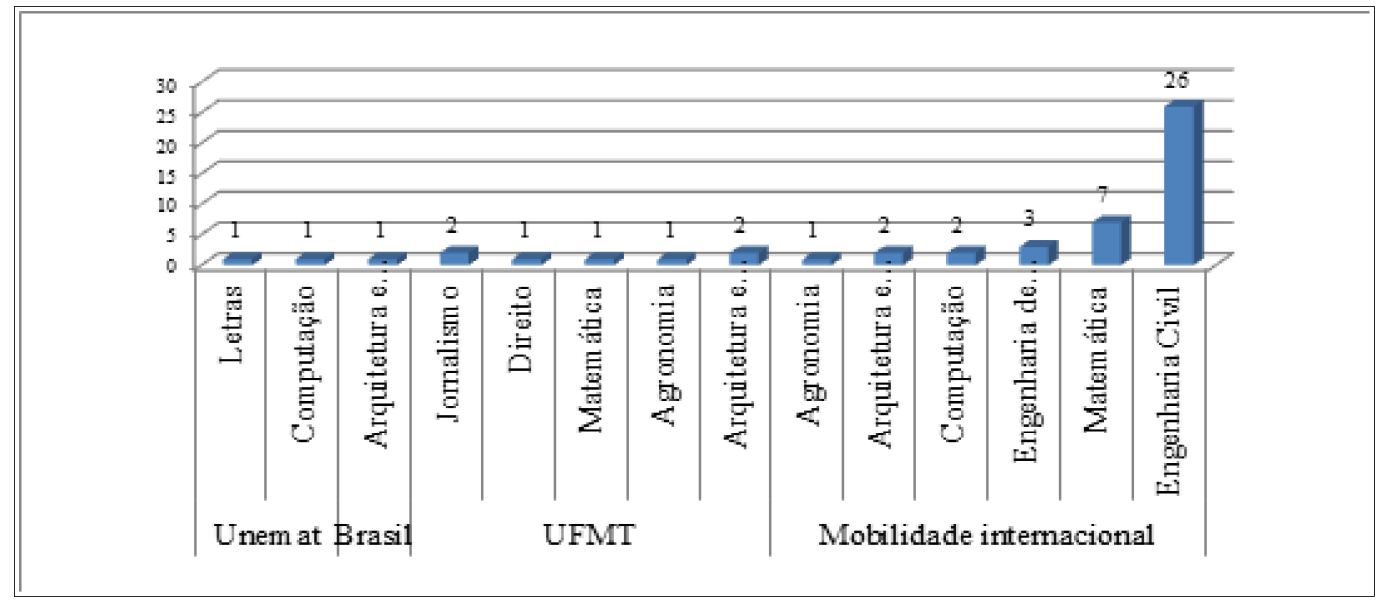

Fonte: dados da pesquisa. 


\subsection{As percepções dos professores e as aprendizagens na mobilidade}

No sentido de apresentar os estudos realizados acerca da aprendizagem na mobilidade, as entrevistas aplicadas aos docentes da Universidade de Aveiro tiveram como foco principal, no contexto do processo de internacionalização das universidades, os objetivos da proposta formulada pela Capes e os pontos positivos e negativos do PLI, a perspectiva dos professores acerca dos estudantes brasileiros que participam do programa, o conhecimento da grade curricular da Licenciatura em Matemática de cursos do Brasil, a motivação utilizada na disciplina e as dificuldades encontradas pelos estudantes brasileiros no acompanhamento dos conteúdos. Para Osti (2010), Saravali (2003), Igue et al. (2008), Siegler (2009), Gomes e Soares (2013), que abordam o tema da aprendizagem e problemas ligados à mesma, um dos aspectos a ser ressaltado é que as dificuldades podem ser geradas ou agravadas por problemas de adaptação social, de convivência, problemas afetivos, do contexto familiar ou que digam respeito às instituições educativas.

Para participar de uma experiência de mobilidade foram selecionados os estudantes de melhor desempenho, compreendendo-se que esses teriam maiores possibilidades de se adaptar ao novo estilo de exigência que poderiam encontrar na IES estrangeira, às diferentes opções metodológicas que poderiam ser utilizadas, ao próprio ambiente acadêmico diferente quanto aos colegas, à nacionalidade dos professores e colegas, à tipologia das aulas e outras diferenças. Em Osti (2010, p. 50) encontramos fatores que são apontados como obstáculos às aprendizagens, quais sejam: "o contexto familiar e social, a personalidade do sujeito, e as instituições educativas, incluindo suas áreas metodológicas e organizacionais". A autora supracitada afirma que é importante observar o aluno e avaliar, "[...] pois o problema pode estar relacionado não só à disciplina em si, mas também ao professor, ao próprio aluno, ao método, ao ambiente, dentre outras variáveis" (p.53).

Uma das variáveis que consideramos pertinente levantar refere-se às diferenças de requisitos exigidos nas duas instituições que ofertam a licenciatura em Matemática. Na Universidade de Aveiro o foco do curso é mais, como designamos no Brasil, o bacharelado², enquanto na

2 Pela ênfase que o curso de Licenciatura dedica às disciplinas ligadas ao domínio de conteúdos matemáticos. 
Unemat o curso é focalizado como licenciatura, preparando os estudantes para serem professores. Na UA essa preparação se dá com o curso de mestrado, que é oferecido nas diferentes modalidades pelo Departamento de Educação ou de Matemática, e só após a conclusão desse mestrado o estudante estará apto a ministrar aulas aos alunos das escolas em Portugal. Enquanto isso, no Brasil, tínhamos até a década passada um grande número de professores apenas com Ensino Médio dando aulas nas escolas.

Relativamente à motivação dos estudantes para a aprendizagem, Sales (2010, p.15) argumenta na direção da existência de fatores que podem desmotivar o aluno, dentre eles destacando: "não ver importância no conteúdo, não saber por que estudar aquilo, tarefas muito exigentes ou muito entendiantes ou, ainda, falta de crença na própria capacidade". Conseguir essa adequação entre satisfazer um nível mínimo de exigência para a aprendizagem e não requerer tarefas impossíveis constitui um dos desafios para os docentes. Assim como a utilização de métodos adequados, que deveria ser um fator da busca permanente de atualização e capacitação dos professores. Sabemos também que a motivação do aluno pode esbarrar na própria motivação de seus professores. Referindo-se a isto, o mesmo autor salienta que

\begin{abstract}
"existam reais obstáculos à eficácia do ensino, como condições ambientais adversas, o fato de o professor acreditar que a situação não pode ser revertida ou que pouco pode fazer para melhorá-la acabará reforçando a continuidade dessas adversidades, não contribuindo em nada para a mudança." (Sales 2010, p. 18)
\end{abstract}

Para Siegler (2009, p.24), o processo de mobilidade abre espaços para as instituições e departamentos apresentarem iniciativas individuais, enfim proposições que venham contribuir para a promoção da aprendizagem. Textualmente, declara: "O espaço para a criatividade parece estar nas mãos das instituições que devem escolher as melhores formas

Essa estrutura curricular deve-se ao fato de a UA reger-se pelo Processo de Bolonha, pelo qual no mestrado se define a especialização para "matemática e aplicações ou matemática para professores". 
para se adaptar ao ambiente acadêmico internacional acomodando, desta forma, diferentes graus de autonomia e iniciativa". No entanto, os departamentos, as coordenações e os professores que, na efetivação de espaços criativos para o ensino/aprendizagem, maior atenção derem na formulação e nos ajustes necessários para equacionar os diferentes domínios de conteúdos observados nos alunos serão mais exitosos.

Com o objetivo de alcançar um maior nível de satisfação e motivação por parte dos estudantes, há necessidade, neste sentido, de um período de adaptação para aproximações e novos equilíbrios no contexto acadêmico. De forma empírica foi observada uma disposição na coordenação do Departamento de Matemática e nos professores para que os estudantes em mobilidade fossem bem integrados. Um exemplo disso foram os ajustes de horário promovidos pela coordenação no início do ano letivo 2013/2014.

Em específico no contexto de sala de aula, onde se efetiva o processo de ensino e aprendizagem, questionamos, como será a relação professor/aluno? De acordo com Sales (2010, p. 18), "É fundamental que o professor se conscientize que tem bom espaço de liberdade de ação em sua sala de aula, podendo transformar a realidade de muitos alunos que chegam na escola desacreditados e sem condições aparentes para uma aprendizagem significativa". Essa "aprendizagem significativa" deveria ser perseguida tanto pelos professores enquanto promotores como pelos estudantes na condição de sujeitos. Com essa conquista, terão atingido os objetivos últimos e mais caros da educação e, também, da mobilidade. Igue et al. (2008) corroboram ao mencionarem o apoio dos recursos iinstitucionais como um fator que tem motivado os estudantes iniciantes e tem dado contribuições ao sucesso. Todavia, Gomes e Soares (2013) evidenciam a importância de um apoio adequado da instituição para o aluno aprender a ajustar suas expectações em conformidade com a realidade dos recursos disponibilizados para darem suporte às suas necessidades no decurso do Ensino Superior.

Encontramos, ainda, nas palavras de Sales (2010, p.15), um destaque à relevância de um 
bom planejamento das aulas como elemento que oferece funcionalidade às mesmas. São quesitos como esses que possibilitam aos estudantes a obtenção de "êxito em suas tarefas quando sua motivação for positiva, ou seja, quando se envolvem na tarefa livres de distrações, ansiedades ou medo de fracassar". Neste trabalho apresentamos o percurso que, nas percepções dos docentes da UA, quando relatam o ajustamento dos estudantes brasileiros na mobilidade, pode motivar a aprendizagem desses alunos.

\section{PERCURSO METODOLÓGICO}

Quanto à metodologia utilizada, optamos por uma abordagem qualitativo-descritiva. Esta se configura como uma prática contínua, reflexiva e transformadora para os agentes envolvidos. No caso deste artigo, o conteúdo do discurso dos professores que ministraram aulas no primeiro ano de estudos dos alunos do PLI da Unemat na UA. Os métodos de análise centraram-se nas informações colhidas a partir das entrevistas realizadas em outubro de 2014 com os professores e de uma reunião com o Chefe da Divisão para os programas de Mobilidade e Inserção Profissional da UA. Esta reunião foi sugerida pelos estudantes e pela Coordenação da Unemat devido a algumas dificuldades de interação que tiveram com os estudantes da UA. A análise de conteúdo foi realizada com o apoio do software WebQDA.

\subsection{Instrumentos de recolha de dados}

Para o presente estudo, apresentamos os dados analisados das entrevistas com quatro dos sete professores que ministraram disciplinas do 1 으 ano na UA. Tentamos vários contatos com os sete, mas só obtivemos confirmação para a realização da entrevista por parte de quatro deles. Os dados foram levantados no mês de outubro de 2014, decorrido um ano de permanência dos alunos da Unemat na UA. Temos também dados do Chefe da Divisão para os programas de Mobilidade e Inserção Profissional da UA, decorrentes de um encontro com o mesmo ocorrido em outubro de 2014, a pedido da coordenação do projeto e dos estudantes da Unemat.

Foi elaborado um guião de entrevista que constou de duas partes. A primeira foi definida por 
legitimação, com identificação dos professores participantes, a idade, tempo de exercício no magistério, no magistério superior, área de atuação. A segunda parte compõe-se de questões sobre o que os professores pensam acerca da mobilidade acadêmica e da participação dos alunos do PLI em mobilidade na UA.

Para tal elaboramos questões que abordavam os seguintes aspectos: a) opinião com relação à mobilidade (acadêmicos) e à internacionalização das universidades; b) conhecimento da proposta do PLI da Capes; c) os pontos positivos e negativos do PLI; d) opinião acerca dos estudantes brasileiros do programa PLI; e) conhecimento da grade curricular da Licenciatura em Matemática de cursos do Brasil; f) motivação utilizada na disciplina; g) dificuldades dos acadêmicos brasileiros; h) associação das dificuldades à parca preparação dos nossos estudantes brasileiros; i) diferenças no desempenho acadêmico entre os estudantes brasileiros e portugueses; j) sugestões para futuros estudantes PLI terem maior sucesso; k) opinião sobre fracassos dos alunos PLI; I) participação dos brasileiros nas OTs; m) participação dos portugueses nas OTs; n) percepção acerca da relação entre os brasileiros e os portugueses em sala de aula, nos corredores do Departamento, e com os Erasmus. As entrevistas foram realizadas nos Gabinetes dos professores que ministraram disciplinas em 2013/2 e 2014/1.

\section{RESULTADOS E DISCUSSÕES}

Dentre os aspectos que estamos a abordar, e de acordo com os objetivos propostos para este trabalho, apresentamos a percepção dos docentes a partir da análise das falas. Da análise de conteúdo, emergiram as seguintes categorias: Percepção positiva pelo esforço e lutas pessoais; Grandes defasagens na chegada; Muito positivos e autoestima elevada; Abertos para aprendizagens e amizades; e Aspectos culturais. A partir destas categorias tencionamos verificar se estão presentes alguns dos pontos assinalados por Reyes (2012) como pontos fortes, pontos em fase de desenvolvimento e pontos frágeis da mobilidade acadêmica.

No sentido de preservar o anonimato dos professores, foi decidido o uso de pseudônimos ${ }^{3}$. É 3 A escolha dos pseudônimos recaiu sobre Laranja, Uva, Kiwi, Pera e Maçã (frutas encontradas em 
importante observar para que não haja falhas nas interpretações, que, dos participantes, três estão compreendidos entre 16 e 20 anos de atuação no magistério superior (computando aqui o Diretor da Mobilidade da UA); um entre os 11 e 15 anos e um com mais de 30 anos. Pelas idades, temos dois no intervalo entre 40 e 45 anos, um entre 46 e 50 anos, um entre 51 e 55 anos e um com mais de 55 anos.

No gráfico 5, apresentamos os resultados quanto à associação entre as idades dos entrevistados e as referências às categorias observadas na mobilidade. Os resultados revelam que a categoria Grandes defasagens na chegada destaca-se com 20 referências, seguida pela categoria Positiva pelo esforço e lutas pessoais, referida 15 vezes. A categoria Abertos para aprendizagens e amizades obteve um número total de 10 referências, enquanto a categoria Aspectos culturais ficou com 9 referências, e a categoria Muito positivos e autoestima elevada com 8 referências.

Gráfico 5. Idade dos entrevistados e as categorias da mobilidade.

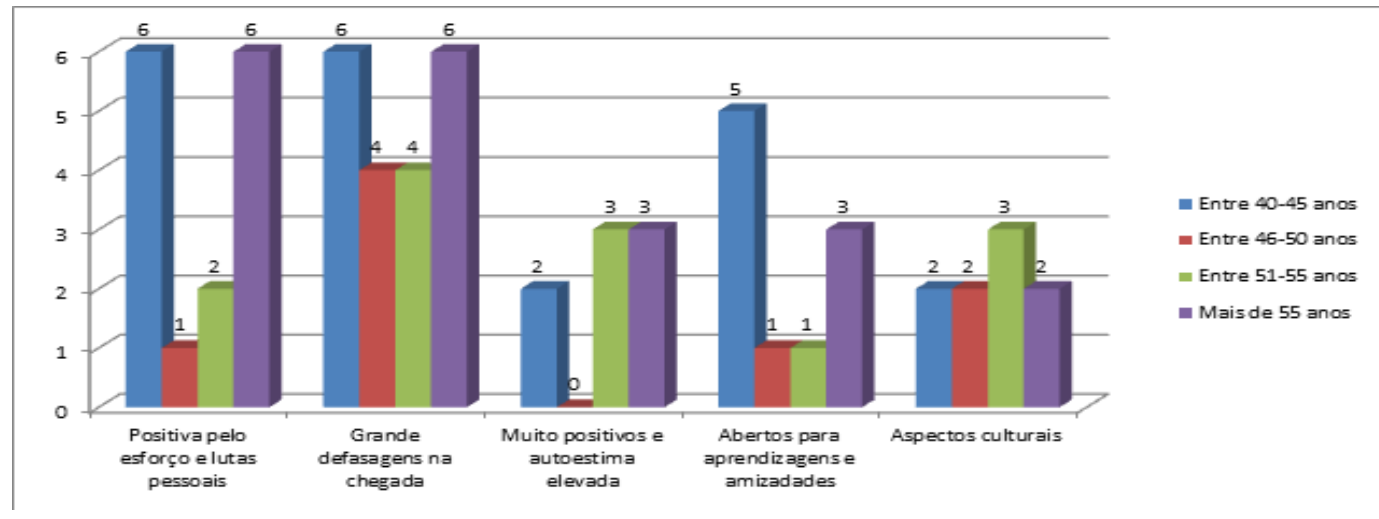

Fonte: dados da pesquisa.

A professora Uva, uma participante com mais de 55 anos, declara na entrevista o esforço e as lutas pessoais dos estudantes brasileiros comparativamente aos estudantes portugueses, quando relata:

abundância nas plantações da cidade de Aveiro e proximidades). Para os estudantes, caso haja menções a eles, os pseudônimos são Pequi, Cedro, Peroba, Ipê e Sucupira (árvores típicas do cerrado mato-grossense). 
Seja do vosso ensino médio, os alunos não trazem a formação que trazem os nossos alunos. Mais um ponto positivo que eu gostaria que fosse destacado é que os alunos que vêm são fantásticos em empenho, o facto deles estarem com muito mais dificuldades fazem com que eles estudem, trabalhem, empenhem-se mais. Vêm em todas as aulas, vêm tirar dúvidas, estão em cima, buscam o conhecimento, eles lutam pelos objetivos, e isto não é nem um, nem dois, é a maioria, claro que há um outro que desvia, mais a grande maioria são absolutamente fantásticos, traz uma nova roupagem ao que não temos aqui. Vejam que quem vem com menos preparação chegam ao final bem, e tem quem venha com mais preparação e não faz diferença no final. Portanto, são muitos dedicados, muito empenhados. Se nossos alunos estudassem o que esses alunos estudam seriam gênios, porque os nossos estudam pouco, acabam se envolvendo com isso e aquilo.

Diante dos resultados obtidos, podemos concordar com a definição de Veiga (2011) no tocante ao processo. A entrevistada Uva afirma que os estudantes fazem acontecer pelo menos duas das três funções primárias de uma instituição, a saber: ensino/aprendizagem, investigação e serviço à sociedade. O esforço deles, tão destacado por Uva, revela-se na tentativa de superar as deficiências observadas na chegada.

Sobre o mesmo tópico, Uva aponta em outro momento que

"[...] os alunos brasileiros aparecem nas OTs, os alunos sabem que estão com dificuldades e estão lá, dos alunos portugueses só vêm os fracos, mas vão duas ou três vezes e depois desaparecem. Os brasileiros vão até o fim, é muita diferença."

A professora entrevistada percepciona a diferença dos estudantes brasileiros na sua presteza no enfrentamento das dificuldades. Acreditamos que, possivelmente, de acordo com Uva, as 
atitudes dos estudantes em superar as dificuldades iniciais exprimam o que vem apontando em Brasil (2011, p.1) sobre a "formulação e implementação de novas diretrizes curriculares para a formação de professores, com ênfase no Ensino Fundamental e no Ensino Médio": o programa de mobilidade evidenciaria algumas lacunas de conteúdos não aprendidos nos anos de escolaridade anteriores e a necessidade de se aprofundarem conteúdos dos tópicos em estudo.

Acerca dos esforços e lutas pessoais dos alunos, a entrevistada Laranja, com idade entre 40 e 45 anos, afirma que "[...] mesmo essa parte, que vossos estudantes aqui têm que trabalhar mais, têm que fazer de fato um esforço maior porque exige mais do que exigiria se estivesse no Brasil, penso eu". Nesta fala, a professora destaca o empenho dos estudantes do Brasil e um menor tempo para os estudos: três dos acadêmicos tinham uma jornada com 40 horas semanais de trabalho. São de conhecimento da professora Laranja as condições de trabalho dos estudantes na Unemat. Em estudo realizado sobre a perspectiva dos alunos em mobilidade na UA, há um consenso de que esses estudantes sentem-se privilegiados em participar do programa. Laranja compara ainda:

"mas normalmente um aluno português é menos empenhado não sei se é essa a palavra certa, também há alunos empenhados, claro que sim, mais não sei, talvez esperam que as coisas caiam do céu, e o brasileiro vai à procura delas". Salienta, por exemplo, o caso do aluno Pequi : "[...] no início era muito sossegado, e depois aos poucos foi um aluno esforçado e com capacidades e também tem muita boa nota". É esse diferencial que os estudantes brasileiros trazem que pode ser um contributo a ser explorado em investigações futuras pelos envolvidos nos programas de mobilidade, indicação já feita pela Capes no documento Brasil (2014).

Podemos ver também o que diz Pera, um docente com idade entre 51 e 55 anos, ao se referir à grande defasagem no momento da chegada dos estudantes. 
Associo, sobretudo, deficiências no percurso acadêmico. Não me recordo nesse momento de nenhum aluno brasileiro que tenha sido desinteressado. Agora, sentimos fragilidade, uma dificuldade grande de ler as fontes documentais e interpretá-las e depois formatar um discurso entre o pessoal e científico.

Podemos notar que esse professor é da área das Humanas, formação que também é requerida dos estudantes PLI no edital. Os professores com essa formação observam fragilidades no nível de ensino na chegada à UA. Percebem que o problema tem uma dimensão mais abrangente e nas Ciências Exatas se acentua ainda mais.

Assim, como especialista em avaliação, o docente sugere:

Em termos científicos, que só há uma hipótese de minimizar o fracasso, é aquilo que muito provavelmente mais ajudaria. Seria uma estratégia institucional, [...] selecionar alguns professores de Matemática ir até a universidade, estar lá uns três, quatro dias em contatos com os alunos, hoje uma hora, amanhã duas.

Esta estratégia sugerida pelo professor em foco seria uma das formas de detectar os pontos frágeis desses estudantes.

Entre os entrevistados, temos ainda o professor Kiwi, com idade entre 46 e 50 anos, que, ao falar sobre a defasagem na chegada dos estudantes, também afirma:

"E os aspectos mais negativos é, no fundo, como falamos há pouco, é a falta de formação que esses alunos têm. Ela é bem menor que os outros alunos e, portanto, há um choque, $e$ nós tentamos ajudar, mais por outro lado temos a matéria pra dar". Também sublinha que "[...] o desempenho deles é comprometido, eles partem em desvantagem, via de regra, porque não têm uma formação que os alunos de cá já têm, em geral. Portanto, a priori estão em desvantagem". Este professor que ministrou a disciplina Análise, destaca essa 
desvantagem inicial dos estudantes brasileiros.

Os resultados revelam uma percepção concordante entre os entrevistados acerca das deficiências na formação dos acadêmicos brasileiros, com um total de 20 referências, conforme apresentado acima no gráfico 5. A associação entre o tempo de magistério no Ensino Superior e a percepção dos entrevistados quanto às categorias eleitas aparece no gráfico 6 a seguir, com 15 referencias no item Positivo pelo esforço e lutas pessoais, 10 referências para a categoria Abertos para aprendizagens e amizades, seguida pela categoria Aspectos culturais com 9 referências e, por fim, com 8 referências, a categoria Muito positivos com autoestima elevada.

Gráfico 6. Tempo de atuação no Ensino Superior e as categorias da mobilidade.

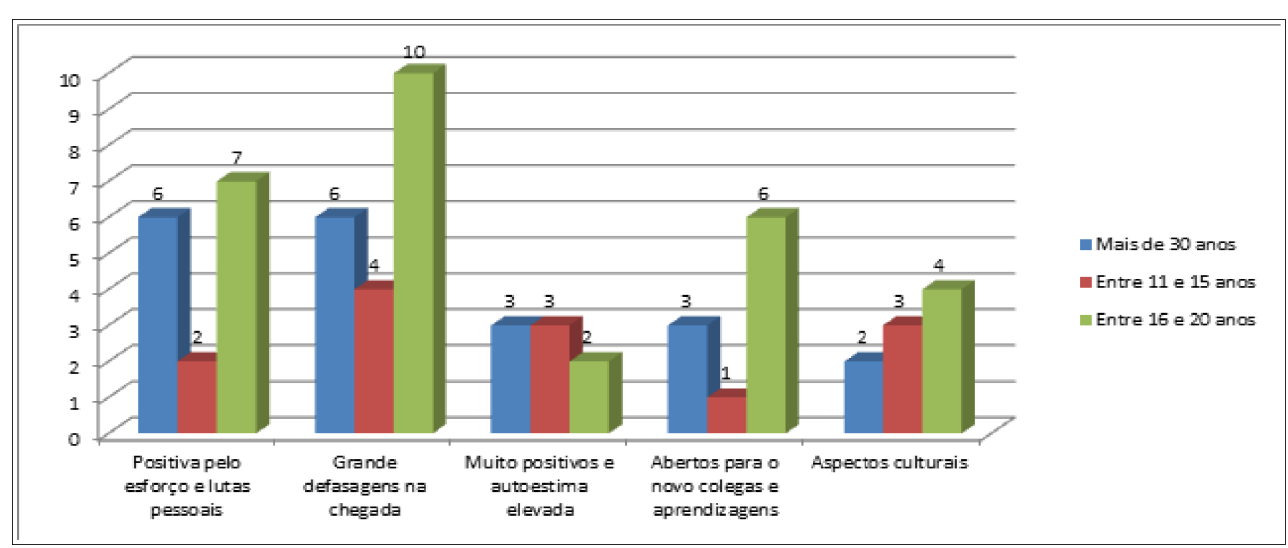

Fonte: dados da pesquisa.

Foram recorrentes as vezes que o professor Kiwi, com atuação no Magistério Superior entre 16 e 20 anos, abordou a Grande defasagem na chegada dos estudantes brasileiros. Em um dos momentos ele apontou que a defasagem como um dos

[...] aspectos mais negativos, no fundo, como falamos há pouco, é a falta de formação que esses alunos têm, é bem menor de facto que os outros alunos e portanto se tem um choque, e nós tentamos ajudar. Mas por outro lado temos a matéria que tem que ser dada, e as coisas talvez sejam difíceis para eles, em particular, mas que eles se ajustam ao nosso caso. 
Observa-se que Kiwi também faz menção indireta à capacidade de superação dos estudantes, pois eles dão conta: "[...] em particular se ajustam ao nosso caso". Em outro momento Kiwi especifica:

[...] o importante e óbvio que as lacunas, em aspectos muito concretos, se quiser que dê um exemplo da Lógica Matemática, a maior parte dos alunos não têm percepção que já deveriam ter a Lógica Matemática, isso é muito complicado, pois quando nós começamos a fazer as demonstrações aqui, eles não conseguem se destrinchar.

São constatações como estas que fazem aflorar os pontos frágeis da mobilidade e do processo de internacionalização. Esses pontos frágeis são, para Reyes (2012), a operacionalização, implementação e efeito de integração nesses momentos. Os estudantes e seus professores se depararam com a problemática de gerenciar essas fragilidades para que todos (estudantes e Universidades) atinjam os objetivos.

A docente Laranja, com tempo no Ensino Superior também entre 16 e 20 anos, ao abordar a Grande defasagem na chegada dos estudantes declara:

[...] eu acho que os alunos são muito trabalhadores e vêm com muitas dificuldades, pois não estão habituados na parte da demonstração, eu por acaso tive sorte, fui professora no segundo semestre no primeiro semestre eles já tinham uma certa adaptação e portanto eu percebi no segundo semestre que já percebiam o que tinham que estudar, como estudar e percebi que aos poucos foram se adaptando.

Ainda se referindo ao mesmo tema, Laranja sugere alternativas para minimizar essa grande defasagem na chegada: 
[...] primeira coisa: chegarem antes de começar as aulas para conseguiram se adaptar, eu lembro que vi uma menina que não conseguia achar comida e isso já estava tendo confusão, então chegar mais cedo é bom, e também com esta chegada mais cedo se pudesse ter um minicurso prévio sobre alguns conceitos básicos para ter o mesmo nível que nossos alunos, de um mês, mais ou menos. Eu acho que é uma boa ideia estudar os tópicos que nós consideramos mais fundamentais para já começarem e sentirem-se mais preparados e não sentirem tantas dificuldades no início.

A fala de Laranja evidencia a preocupação com os estudantes estrangeiros, nesse caso, os brasileiros. Sua percepção reafirma o que o documento Brasil (2011) preconiza sobre a necessidade de se investir na formação de pessoal, aumentar a presença de pesquisadores e estudantes de vários níveis em instituições de excelência no exterior para contribuir com o avanço científico e melhorar/adaptar a formação dos estudantes nas instituições brasileiras.

Pera, com atuação no Ensino Superior entre 11 e 15 anos, assim descreve as deficiências dos estudantes brasileiros: "De alguns alunos brasileiros, eu não vou discriminar nem por universidade, nem por curso, vi alunos que claramente tinha dificuldades, e alunos espetaculares". A fala de Pera e dos outros professores entrevistados aponta as dificuldades dos brasileiros em acompanharem o ensino ministrado na UA. No entanto, é de crucial importância salientar que o problema não se restringe às Ciências Exatas como Matemática e Física, uma vez que Pera declarou ter observado o mesmo na interpretação documental: "Agora, sentimos fragilidade, uma dificuldade grande de ler as fontes documentais $e$ interpretá-las e depois formatar um discurso entre o pessoal e científico".

No que concerne à categoria Abertos para aprendizagens e amizades, Kiwi, que atua no Ensino Superior entre 16 e 20 anos, considera a mesma como aspecto positivo: "terem um contato com realidades diferentes e terem esse contato de maneira conectiva, quer seja com 
interação com os professores ou com os colegas que vêm do Brasil, eu acho que isso é enriquecedor, claramente, e traz uma maturidade que obviamente os de origem não teriam".

A entrevistada Laranja, com atuação entre 16 e 20 anos no Ensino Superior, corrobora a fala de Kiwi quando sublinha: "Eu acho que é muito positivo pra ambas as partes, pois temos todos a aprender com esse intercâmbio, eu não sei citar apenas algum sentido, pois são tantos". Esta percepção vai ao encontro do declarado por Derin et al. (2009), que mencionam a mobilidade enquanto dimensão cultural, pois é importante para alcançar os objetivos dos projetos que envolvem mobilidade os estudantes do PLI construírem bons relacionamentos com os alunos portugueses, ajudar os outros alunos estrangeiros a adquirir conhecimento e habilidades na vida. Enfim todos podem se ajudar para adquirirem conhecimentos e habilidades que eles precisam para as novas aprendizagens. Esses objetivos estão presentes no projeto aprovado, e o reconhecimento por parte dos professores da UA, contribuiu para tornar o processo de mobilidade um sucesso para os alunos estrangeiros, inclusive os brasileiros.

Na categoria Aspectos culturais os resultados revelam 9 referências, e dessas, 4 foram de dois professores com 16 a 20 anos de docência no Ensino Superior. Kiwi, por exemplo, elogia: "Eu acho que é bastante importante porque permite compartilhar experiências e informações"; ressalva também "que essa convivência pode ser potencializada, mas às vezes os brasileiros se limitam a ficar entre eles", atitude que, segundo Kiwi, intimida os portugueses e "é cómodo" a ambos os grupos de estudantes (portugueses e brasileiros).

Maçã, que tem atuação entre 16 e 20 anos no Ensino Superior e atualmente é responsável pelos programas de mobilidade, afirmou: "[...] foi muito bom vocês virem falar comigo sobre essas coisas". O entrevistado se referiu ao encontro que abordou as dificuldades de interação dos estudantes brasileiros com os portugueses, o que é isso é visto como ponto negativo no Aspecto cultural, pois uma convivência mais intensa oportuniza horizontes que os conhecedores do local podem melhor ajudar a explorar. 
Uma outra categoria se refere aos aspectos Muito positivos da mobilidade. Para esta categoria houve um total de 8 referências, das quais 3 foram de entrevistados com atuação na docência de mais de 30 anos. Uva é professora com esse perfil e diz:

Mas, em termos percentuais, eu acho os alunos brasileiros muito mais preparados para lutarem contra as adversidades do que os nossos. Porque o nosso ensino secundário é muito difícil, é como a porta de entrada para o ensino superior, então quem passa é um alívio, o exame final é um exame difícil. Então não há uma grande diferença, os mais empenhados são os brasileiros.

As outras referências são também acerca do empenho e da presença frequente dos brasileiros em todas as atividades. Nessa categoria temos a declaração de Pera, com tempo de atuação no Ensino Superior entre 11 e 15 anos:

Mas esta turma é curiosa, que das diversas disciplinas que eu leciono, esta seja talvez a disciplina mais estimulante por causa da diversidade, por causa desse contraste, e lembro claramente de vários alunos brasileiros que são espetaculares, no sentido de muito discreto, que de repente, por sua iniciativa, ou porque é solicitado, toma a palavra e dá uma intervenção fantástica.

Nas palavras de Pera há um reconhecimento do potencial de estudantes em mobilidade. São estados de abertura e reconhecimento de limites e potencialidades que sugere Siegler (2009) ao falar sobre a necessidade do planejamento, da estruturação organizacional, de apoio a ações como reforma curricular, de iniciar pesquisas conjuntas, celebrar acordos internacionais além dos intercâmbios de estudantes e professores. São talvez essas iniciativas que caminham a passos lentos no processo de uma sustentável internacionalização das instituições, e cuja importância pode ter dimensões até então pouco valorizadas. 
Com tempo de atuação entre 16 e 20 anos no Ensino Superior é que finalizamos a análise dos resultados, com a fala de Laranja: "Sim, eles participam mais que os portugueses, é o que eu tenho a dizer, é positivo eles participarem. Não iam sempre, mas iam quando tinha dúvidas e não tinham medo de fazer perguntas".

E de Maçã, que diz: "[...] quem está bem com a vida está melhor no seu trabalho. Faz parte da vida e do discurso que quando trabalhamos bem se tem qualidade de vida." De acordo com as percepções dos professores entrevistados, é comprovado que os estudantes em foco apresentam aspectos positivos no programa de mobilidade internacional.

\section{CONSIDERAÇÕES FINAIS}

Diante dos objetivos propostos neste trabalho, os resultados apontam para algumas reflexões imprescindíveis acerca da percepção dos professores sobre a mobilidade internacional de estudantes estrangeiros, nomeadamente os brasileiros; são elas, entre outras: a) a constatação das fragilidades observadas na chegada quanto à formação matemática dos estudantes em mobilidade acadêmica; b) a grande capacidade de busca, luta e superação que os estudantes brasileiros desenvolvem no programa de mobilidade; c) os esforços pessoais, tão bem destacados pelos entrevistados, que os estudantes do programa desenvolvem para alcançarem êxito nos estudos ao final do primeiro ano de mobilidade, condição exigida pela Capes para poderem permanecer e obter a dupla diplomação; d) o diálogo estabelecido entre as coordenações de ambas as Instituições de Ensino para definição das disciplinas e ajustes nos horários, necessários para um melhor aproveitamento dos estudos pelos alunos brasileiros também é um ponto digno de reflexão, embora não conte nas percepções explicitadas pelos docentes.

Enfatizamos, por fim, que alguns aspectos ficam ainda por responder em outros estudos, como por exemplo: O que faz com que os estudantes brasileiros desenvolvam o poder de 
superação dos limites apresentados na chegada à UA?; Quais são os motivos que levam os estudantes portugueses, que têm um diferencial na entrada do Ensino Superior, a não permanecerem com bom desempenho/rendimento na UA? Como as Instituições envolvidas no programa poderão promover uma melhor articulação nos requisitos da Mobilidade, no sentido de minimizar alguns agravantes na chegada de alunos estrangeiros, designadamente brasileiros, e possibilitar um melhor ajustamento académico em todos os domínios?

Enfim, os resultados apresentados no presente trabalho revelam a necessidade de ajustes nos programas de mobilidade que possam responder de forma positiva às necessidades dos estudantes brasileiros, inclusive uma revisão na grade curricular dos cursos de Licenciaturas do Brasil.

\section{AGRADECIMENTOS}

Por fim, expressamos nossos agradecimentos à CAPES, à Universidade do Estado de Mato Grosso, à Universidade de Aveiro e aos participantes da pesquisa, que possibilitaram a realização deste trabalho. 


\section{REFERÊNCIAS}

BRASIL. Ministério da Educação. Coordenação de Aperfeiçoamento de Pessoal de Nível Superior. Programa de Licenciaturas Internacionais CAPES/UC. 2010. Disponível em: <capes.gov.br/images/stories/download/bolsas/Edital035_Licenciaturalnternacional_Capes_ UC.pdf> Acessado em 20/02/2015.

Programa de Licenciatura Internacionais - PLI Portugal. 2010.

Disponível em: <capes.gov.br/images/stories/download/editais/19122014-074-2014-PLI2014.doc>. Acesso em: 7 mar. 2015.

Decreto no 7.642. Brasília: 2011.

DE WITT, Hans. Rationales for internationalization of higher education. Millenium 3, $\mathrm{n} 019$, 1998.

DERIN, Atay; ZEYNEP, Çamlıbel; PINAR, Ersin; ÖZLEM, Ka lıo lu; GÖKÇE, Kurt. Turkish EFL teachers' opinions on intercultural approach in foreign language education. Procedia Social and Behavioral Sciences, 1, 2009, p. 1611-1616.

GOMES, Gil; SOARES, Adriana Benevides. Inteligência, habilidades sociais e expectativas acadêmicas no desempenho de estudantes universitários. Psicologia: Reflexão e Crítica, 26(4), 2013, p. 780-789.

IGUE, Érica Aparecida; BARIANI, Izabel Cristina Dib e MILANESE, Pedro Vitor Barnabé Vivências acadêmicas e expectativas de universitários ingressantes e concluintes. PsicoUSF, 13(2), 2008, p. 155-164.

JOFIN, J. Internationalisation of higher education: an evaluative study of internationalization efforts at the University of Chester. University of Chester (Tese de Mestrado), 2009.

KNIGHT, J. Internationalization: Elements and checkpoints. Ottawa, Canada: Canadian Bureau for Internacional Education, 1994.

KNIGHT, J. Quality and Internationalization in Higher Education. OECD. ISBN: 92-64-17049-9, 1999.

OSTI, Andreia. Representações de alunos e professores sobre ensino e aprendizagem. Tese de doutorado. Campinas, SP, 2010.

REYES, Maria Carmen Larouenerie. Fortalecimento das capacidades do Serviço de Mobilidade Academica do Instituto Tecnológico de Boca del Rio. Dissertação (Mestrado Engenharia de Serviços e Gestão), Universidade do Porto, 2012.

RUDZKI, Romuald. The application of a strategic management model to the internationalization of higher education institutions. Higher Education (29), 1995, p. 421-441. 
SALES, Karla Fernanda Suenson. Atribuições causais de professores por fracasso escolar em Matemática: comparação com percepções de seus alunos. Dissertação (Mestrado em Educação). Universidade Estadual de Londrina, 2010.

SANTOS, F. S. e CORDEIRO, C. R. Os novos caminhos da internacionalização universitária. Em: SANTOS, R. R. e BONITO, J. (Org.) Pensar e construir a universidade no século XXI. Boa Vista: Editora da UFRR, 2015.

SARAVALI, Eliane Giachetto. Dificuldades de aprendizagem e interação social. Tese de Doutorado. FE, Unicamp, 2003.

SIEGLER, Janaina e MIURA, Irene Kazumi. Internacionalização do Ensino Superior: um estudo de caso na Universidade Federal de Uberlândia. Em: Anais do VII Encontro de Estudos sobre Empreendedorismo e Gestão de Pequenas Empresas, Florianópolis, 2012. Disponível em: <www.anegepe.org.br/javabusca/files/t16720100266_1.pdf>. Acesso em: 2 jun. 2015.

SIEGLER, Janaina. O processo de internacionalização das Instituições de Ensino Superior: um estudo de caso na Universidade Federal de Uberlândia. Dissertação (Mestrado em Economia, Administração e Economia), Universidade de São Paulo, Ribeirão Preto, 2009.

UNEMAT. Relatório das atividades de mobilidade. Diretoria de Gestão de Mobilidade Acadêmica - DMA. Cáceres, 2014.

UNIVERSIDADE DE AVEIRO. Regulamento de estudos da Universidade de Aveiro. Aveiro - PT, 2011.

VEIGA, Rita Baeta. Internacionalização das Instituições de Ensino Superior em Portugal: proposta de metodologia para construção de indicador do grau de internacionalização. Dissertação (Mestrado em Negócios Internacionais). Instituto Politécnico de Leiria, 2011. 